\title{
Analysis of relationship between memory functions and blood indices across parturition in primigravidae
}

\section{Srinivasan Venkataraman*, Semmal Syed Meerasa}

Department of Physiology, Sri Ramachandra Medical College and Research Institute, Chennai, Tamilnadu, India

Received: 25 January 2017

Revised: 04 March 2017

Accepted: 06 March 2017

\section{*Correspondence:}

Dr. Srinivasan Venkataraman,

E-mail: venkindsri94@gmail.com

Copyright: (C) the author(s), publisher and licensee Medip Academy. This is an open-access article distributed under the terms of the Creative Commons Attribution Non-Commercial License, which permits unrestricted non-commercial use, distribution, and reproduction in any medium, provided the original work is properly cited.

\section{ABSTRACT}

Background: Psychoneuroendocrinology is a nascent and vibrant field of endocrinology, revealing the unexplored paths of the diversifying field relating to cognitive functions and blood indices which is an interesting learning arena. This work, establishes the relationship of cognitive status and blood indices across parturition among the same subjects.

Methods: The experimental design aimed at administration of cognitive assessment function tests as per Wechsler's memory scale to pregnant subjects and getting specific blood parameters analysed across parturition. The statistical analysis included regression analysis to eliminate the effect of age on the parameters considered and a paired $\mathrm{T}$ test to establish relationship across parturition among the same subjects.

Results: Cognitive assessment of the subjects clearly revealed that the following aspects of cognitive functions during conception are significantly impaired post parturition general memory, mental control 1, 2, 3, immediate recall memory. (Mental control 4 and 5). Symbolic memory (observations). Whereas the following cognitive functions of the same subjects during conception, are NOT significantly impaired post parturition, orientation, digit cognition (mental control 6 and 7). In the case of blood indices, as per the results obtained, it is quite clearly evident that the following blood parameters of the same subjects showed statistically significant difference during conception compared to post parturition. Mean corpuscular haemoglobin $(\mathrm{MCH})$, mean corpuscular haemoglobin concentration (MCHC), mean corpuscular volume (MCV). Whereas the following blood parameters of the same subjects showed NO statistically significant difference during conception compared to post parturition, haemoglobin (Hb), total count (TC), platelet count (PC)

Conclusions: The domain of cognition related to immediate and recent memory functions, Mean corpuscular blood indices have shown significant variation during pregnancy compared to post parturition. Therefore, the parameters considered in this study indirectly reflects upon the hormonal influence on cognition and blood indices, further studies will help venture more into this newer field of psycho endoneuroimmunology.

Keywords: Blood Indices, Cognition, Memory, Parturition, Psychoneuroendocrinology

\section{INTRODUCTION}

Psychoneuroendocrinology is a nascent and vibrant field of endocrinology, revealing the unexplored paths of the diversifying field relating to cognitive functions and blood indices which is an interesting learning arena. During the period of pregnancy, women undergo various physical stress factors such as exertion and fatigue. In accordance with the available literature, these factors have been linked with cognitive impairment which is believed to be the result of increased levels of corticosteroids, Oxytocin, and endogenous opiates (substances associated with conception and parturition). ${ }^{1,2}$ Betaendorphins, substance associated with conception 
and parturition has been found to show high levels during periods of stress. ${ }^{3,4}$ The effect of these endorphins have been demonstrated in lower mammals having association to cognitive dysfunction. Presence of blood brain barrier serves as a hindrance in estimation of levels of these substances in blood. Therefore, as an indirect method, evaluation of cognitive status is more effective and reliable.

This study would prove fruitful as same subjects have been tested longitudinally in both pre and postpartum period conferring reliable results compared to previous studies that tested at a single point of time. ${ }^{5,6}$ The experimental design involves administration of cognitive assessment function tests to subjects and evaluation of blood indices across parturition. Primigravidae chosen as subjects, to clear conflicts of hormonal disturbances of previous pregnancies.

\section{METHODS}

The study done is a paired group study where subjects are assessed pre and post parturition. The total subjects involved in the study are 49. All primigravidae were included while subjects with metabolic disorders and gross anaemia were excluded.

The wechsler memory scale (WMS) is a neuropsychological test designed to measure different memory functions in a person. It can be used with people from age 16 through 90 . The following parameters were evaluated using this test.

\section{General memory}

This test aims at assessing the general memory status of the subject.

\section{Orientation}

This test assesses the current momentary memory of the person.

\section{Mental control 1}

This is assessed by making the subjects count backward from 20 to 1 . The time taken in seconds for the subject to count is recorded using a stopwatch.

\section{Mental control 2}

This is administered by making the subjects recite alphabets A to Z. The time taken in seconds for the same is recorded using a stopwatch.

\section{Mental control 3}

This is a test where the subjects are asked to recite multiples of 3 till 45 . The time taken in seconds by them for the same is recorded.

\section{Mental control 4}

The subject here is asked to read a structured paragraph ONCE and then asked to repeat the same paragraph from memory. The number of words the subject can repeat back is noted.

\section{Mental control 5}

It is similar to mental control 4 where another structured paragraph is given and the subject is asked to read it once and repeat back from memory. The number of words the subject is able to recall is noted.

\section{Mental control 6}

This is a test where the subjects are to write down Digits Forward for 4 sets of digits given.

\section{Mental control 7}

This is a test where the subjects are to write down digits backward for 4 sets of digits given.

\section{Observation 1, 2 and 3}

There are 3 observation tests that are used to assess symbolic memory. There are 3 diagrams which are given to the subjects one by one. The subject is allowed to observe each diagram for 10 seconds. Then the subjects are asked to reproduce the diagrams. The scoring for each diagram is based on the number of lines of the diagrams the subject is able to reproduce.

\section{Blood indices}

The haematological parameters under elucidation are,

- Haemoglobin (Hb)

- Total count (TC)

- Platelet count.

- Mean corpuscular volume (MCV)

- Mean corpuscular haemoglobin (MCH)

- Mean corpuscular haemoglobin concentration (MCHC).

All the above tests and parameters were assessed before and after parturition after obtaining due consent from the subjects. The data were collected in the questionnaire form given. The scores evaluated. Further, the data was subjected to various statistical tests and the results were obtained.

\section{RESULTS}

The outcome of this research work has yielded fruitful results concurrent with previous studies ${ }^{7,8}$. 
Data collected from the subjects are given in Table 1 and 2. As mentioned earlier, there were 12 cognitive tests performed which assesses various aspects of cognition of the same subject.

Table 1: Regression for age versus cognitive test parameters.

\begin{tabular}{|llll|}
\hline AGE Vs & Co-efificient value & Stat. significance & Inference \\
\hline Memory & 0.11 & Not significant & No relationship \\
\hline Orientation & 0.19 & Not significant & No relationship \\
\hline Mental Control 1 & 0.19 & Not significant & No relationship \\
\hline Mental Control2 & 0.05 & Not significant & No relationship \\
\hline Mental Control 3 & 0 & Not significant & No relationship \\
\hline Mental Control 4 & 0.2 & Not significant & No relationship \\
\hline Mental Control 5 & 0.17 & Not significant & No relationship \\
\hline Mental Control 6 & 0.1 & Not significant & No relationship \\
\hline Mental Control 7 & 0.08 & Not significant & No relationship \\
\hline Observation 1 & 0.01 & Not significant & No relationship \\
\hline Observation 2 & 0.08 & Not significant & No relationship \\
\hline Observation 3 & 0.06 & Not significant & No relationship \\
\hline
\end{tabular}

Table 2: T-test between before and after delivery.

\begin{tabular}{|c|c|c|c|c|c|}
\hline $\begin{array}{l}\text { Cognitive } \\
\text { parameters }\end{array}$ & P-value & $\begin{array}{l}\text { Null } \\
\text { hypothesis } \\
\text { for mean }\end{array}$ & $\begin{array}{l}\text { Alt. } \\
\text { hypothesis } \\
\text { for mean }\end{array}$ & $\begin{array}{l}\text { Statistical } \\
\text { inference }\end{array}$ & Conclusion \\
\hline Memory & 0.003 & $B=A$ & $\mathrm{~B}<\mathrm{A}$ & $\mathrm{S}$ & Mean of before is lower than after \\
\hline Orientation & $>0.5$ & $\mathrm{~B}=\mathrm{A}$ & $B<A$ & NS & Mean of before is same as after \\
\hline Mental control 1 & 0 & $B=A$ & $B>A$ & $\mathrm{~S}$ & Mean of before is higher than after \\
\hline Mental control 2 & 0 & $B=A$ & $\mathrm{~B}>\mathrm{A}$ & $\mathrm{S}$ & Mean of before is higher than after \\
\hline Mental control 3 & 0 & $\mathrm{~B}=\mathrm{A}$ & $B>A$ & $\mathrm{~S}$ & Mean of before is higher than after \\
\hline Mental control 4 & 0 & $B=A$ & $\mathrm{~B}<\mathrm{A}$ & $\mathrm{S}$ & Mean of before is lower than after \\
\hline Mental control 5 & 0 & $B=A$ & $\mathrm{~B}<\mathrm{A}$ & $\mathrm{S}$ & Mean of before is lower than after \\
\hline Mental control 6 & $>0.5$ & $\mathrm{~B}=\mathrm{A}$ & $B<A$ & NS & Mean of before is same as after \\
\hline Mental control 7 & $>0.5$ & $\mathrm{~B}=\mathrm{A}$ & $\mathrm{B}<\mathrm{A}$ & NS & Mean of before is same as after \\
\hline Observation 1 & 0.091 & $\mathrm{~B}=\mathrm{A}$ & $\mathrm{B}<\mathrm{A}$ & S & Mean of before is same as after \\
\hline Observation 2 & 0 & $B=A$ & $\mathrm{~B}<\mathrm{A}$ & $\mathrm{S}$ & Mean of before is lower than after \\
\hline Observation 3 & 0.029 & $B=A$ & $\mathrm{~B}<\mathrm{A}$ & $\mathrm{S}$ & Mean of before is same as after \\
\hline \multicolumn{6}{|c|}{ Blood test parameters } \\
\hline $\mathrm{Hb}$ & 0.167 & $B=A$ & $B<A$ & NS & Mean of before is same as after \\
\hline $\mathrm{TC}$ & 0.129 & $B=A$ & $B<A$ & NS & Mean of before is same as after \\
\hline Platelet & 0.772 & $\mathrm{~B}=\mathrm{A}$ & $B<A$ & NS & Mean of before is same as after \\
\hline $\mathrm{MCH}$ & 0.049 & $\mathrm{~B}=\mathrm{A}$ & $\mathrm{B}<\mathrm{A}$ & S & Mean of before is lower than after \\
\hline $\mathrm{MCHC}$ & 0.002 & $B=A$ & $\mathrm{~B}<\mathrm{A}$ & $\mathrm{S}$ & Mean of before is lower than after \\
\hline MCV & 0.000 & $B=A$ & $\mathrm{~B}>\mathrm{A}$ & $\mathrm{S}$ & Mean of before is higher than after \\
\hline
\end{tabular}

B - Before delivery, S- Statistically significant, NS- Statistically not significant A - After delivery

The first test which was performed to assess the general memory, the subjects were evaluated on general questions. The analysis of the scores has brought us to a $\mathrm{P}$ value of 0.003 which is less than 0.1 at 0.05 level of significance.

This clearly suggests that the null hypothesis (Before = After) is rejected and the alternate hypothesis holds true. The difference in the scores pre and post parturition is statistically significant with general memory being impaired during pregnancy than after parturition. Having studied the differences in scores pre and post parturition for all the other cognitive sets of tests, the null hypothesis considered is before $=$ after. In all the tests performed, the $P$ value of the T Test result will help us establish the fact if the null hypothesis is true or rejected. From the $\mathrm{P}$ value results that have been established it is clear that in certain cognitive parameters, there is a clear rejection of the null hypothesis proving a significant impairment in cognition in pre and post parturition period. While in certain $\mathrm{P}$ values where the null hypothesis holds true where the $\mathrm{P}$ Value of the T Test is more than 0.1 , it is clearly evident 
that there is no significant impairment pre and post parturition. Mental control 5 and 6 shows maximum $\mathrm{P}$ value indicating maximum level of variation. Both the tests mentioned above tested the immediate recalling memory of the subjects. This aspect of cognition is found to be most affected. On the other hand, mental control 9 and 10 deals with cognitive aspects of digits and its usage, while orientation tests subject's awareness of current date, time, place etc. Both these parts of cognition when subjected to statistical analysis have showed no significant variation.

\section{Step 1: Analysis thro histogram}

To roughly assess the probability distribution* of the AGE of every subject by depicting the frequencies of observations.

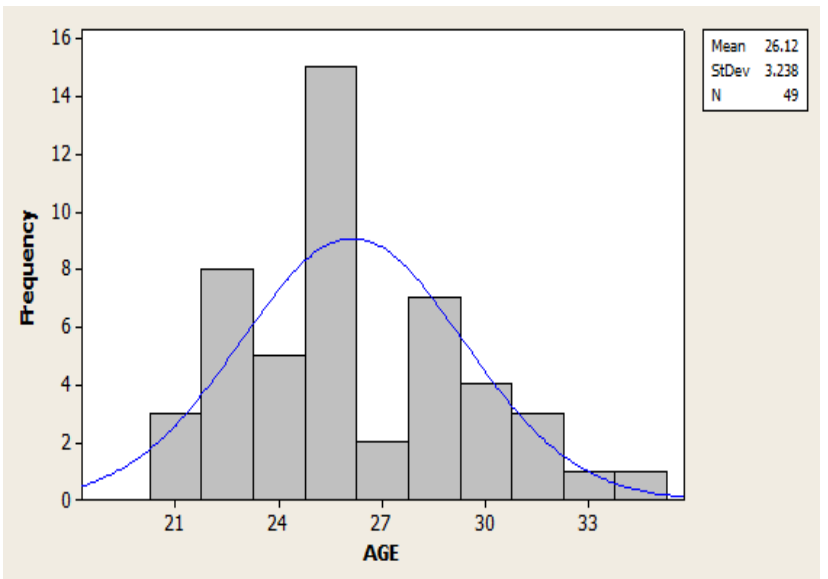

Figure 1: Histogram of age

\section{Step 2: Regression analysis}

According to the results of the regression analysis, it is very clear that there is no significant influence of age of the subjects on the study parameters. It is therefore clear that the population under consideration can be regarded as a universal set for carrying out the research work.

\section{Step 3: Hypothesis tests}

The statistical tests that were employed for hypothesis testing are as follows:

\section{Paired T test:}

In this study the type of T-test used. A test of the null hypothesis that the difference between two responses measured on the same statistical unit has a mean value of zero. For example, in our case the results of the test conducted before and after the delivery. If the hypothesis hold true, we expect the results to be different before and after the delivery. This is often referred to as the paired or repeated measures t-test.

\section{DISCUSSION}

Psychoneuroimmunology is a nascent and vibrant field of immunology in which revealing the unexplored paths relating to cognitive functions and blood indices are an interesting learning arena. The spark for the study emerged at the bedside during a routine visit to the wards, where new mothers with abundant joy complained about problems in certain aspects of cognition. Hormones of conception-which the human body gets exposed only during the period of conception was the only reason that flashed across.

Studies on this topic revealed interesting results paving way for the current work where Katharine $S$ et al investigated the impairment of memory functions across pregnancy by assessing the performance of pregnant women in a variety of tests of memory and compared that with non-pregnant controls. ${ }^{5} 81 \%$ of pregnant women rated their current memory as being impaired whereas only $16 \%$ of the control subjects rated it to be impaired. The deficits were found for both primigravidae and multigravidae women, and were present in all trimesters of pregnancy.

Adding to this, Keenan et al conducted a study among to systematically investigate previous anecdotal reports of memory decline during pregnancy. ${ }^{6}$ It was a longitudinal study designed to investigate memory in women throughout pregnancy and in the postpartum period. Contrasts showed a significant decline in memory for the pregnant group from the second to the third trimester $(\mathrm{P}<.01)$. They concluded that there is a pregnancyrelated decline in memory, which is limited to the third trimester. The decline is not attributable to depression, anxiety, sleep deprivation, or other physical changes associated with pregnancy. Taking the results of this, the presentstudy was emphasized assessing the same subjects during their $3^{\text {rd }}$ trimester and after delivery.

Furthermore, Eidelman et al studied the cognitive function of parturients in the days immediately after delivery among one hundred postpartum mothers who delivered normal full-term infants were tested on the wechsler logical memory test and the wechsler visual reproduction test and found that the postpartum women scored significantly lower than non-pregnant women on both tests on the first postpartum day. ${ }^{7}$

Again this study reassured the significant impairment during pregnancy but done using non-pregnant women as control which is a constraint for the study. Hence in order to eliminate the constraints of the previous studies and this present study has been designed carefully choosing the subjects and following with the subjects from time to time. This henceforth tremendously increases the dependability of the result of this study.

Also with few previous studies like Katharine Sharp et al, Keenan et al and others, it has been found that cognitive 
impairment during pregnancy is evident. Moreover, Eidelman et al and few others have put forth presence of impairment in cognition post parturition. ${ }^{5-7}$ This study aimed to fill the void that is left behind from previous studies (i.e.) to assess the exact time during the peripartum period where this impairment is at its maximum and establishing a possible relationship to blood indices, which serves as a indirect study of hormonal relationship to this study. This study has been therefore specifically designed to fill the voids created by other studies.

Present study clearly shows statistically significant difference in the cognitive domains related to the faculty of General memory among the women across parturition. This faculty was found to be decreased by $3.86 \%$ during the third trimester of pregnancy compared to the cognitive domains of memory functions related to after delivery.

Next to observe that there is NO statistically significant difference in the cognitive domains related to the faculty of orientation among the women across parturition which indicates there is no or minimal impact and continues during and after pregnancy.

Third important finding is to observe a statistically significant difference in the cognitive domains related to the faculty of mental control among the women across parturition. This faculty was found to be decreased by $30.79 \%$ during the third trimester of pregnancy compared to the cognitive domains of mental control functions related to after delivery.

Study is also able to observe a statistically significant difference in the cognitive domains related to the faculty of symbolic memory among the women across parturition. This faculty was found to be decreased by $16.5 \%$ during the third trimester of pregnancy compared to the cognitive domains of symbolic memory related to after delivery.

The above parameters that showed significant variation suggests that cognitive impairment during pregnancy is higher when compared to post parturition.

Authors were able to observe that there is no statistically significant difference in the cognitive domains related to the faculty of digit cognitionamong the women across parturition.

In present study it was observe that a statistically significant difference in the following blood indices

- Mean corpuscular haemoglobin $(\mathrm{MCH})$ - Decreased by $4.1 \%$

- Mean corpuscular haemoglobin concentration (MCHC) - Decreased by $5.01 \%$

- Mean corpuscular volume (MCV) - Increased by $3.5 \%$
- During the third trimester of pregnancy compared after delivery.

In present study it was also observe that there is no statistically significant difference in the following blood indices.

- $\mathrm{Hb}$

- Total count

- Total platelet count

During the third trimester of pregnancy compared after delivery. Based on the results obtained from the study, it is quite clear that the domain of cognition related to immediate and recent memory functions are more affected than distant memory. Therefore, hormones of pregnancy which were the basis behind the study have effects on areas of the brain related to recent memory. ${ }^{9,10}$ As compared to other studies, this study has helped to decipher clearly the particular domain of memory that is hampered during the time of pregnancy. This will help in future for identifying the exact path through which memory related studies in pregnancy should be lead.

\section{ACKNOWLEDGEMENTS}

Authors would like to thank M/s Ramachandra University and M/s ICMR for providing the platform and encouragement to carryout Research work which is the prime requirement of our country today.

Funding: No funding sources

Conflict of interest: None declared

Ethical approval: The study was approved by the Institutional Ethics Committee

\section{REFERENCES}

1. Axelrod J, Reisme TD. Stress hormones: their interaction and regulation. Science. 1984;224:452-9.

2. Mcgaugh JL. Involvement of hormonal and neuromodulatory systems in the regulation of memory storage. Annu Rev Neurosci. 1989;12:25587.

3. Abboud TK. Maternal and fetal beta-endorphins : Effects of pregnancy and labor. Arch Dis Child. 1988;63:707-9.

4. Cahill CA. Beta-endorphins levels during pregnancy and labor: a role in pain modulation? Nurs Res. 1989;38:200-3.

5. Catherine S, Peter MB, Malcolm W. Memory loss during pregnancy. British J Obstet Gynaecol. 1993;100(3):209-15.

6. Keenan PA, Yaldoo DT, Fuerst DR, Ginsburg KA. Explicit memory in pregnant women. Am J Obstet Gynecol. 1998;179(3):731-7.

7. Eidelman AI, Hoffmann NW, Kaitz M. Cognitive deficits in women after childbirth. Obstetrics and gynecology. 1993;81(5):764-7. 
8. Crawley, R., Grant, S, Hinshaw KIM. Cognitive changes in pregnancy: mild decline or societal stereotype? Applied Cognitive Psychology. 2008;22(8):1142-62.

9. Henry JD, Rendell PG. A review of the impact of pregnancy on memory function. J Clinical Experimental Neuropsychology. 2007;29(8):793803.
10. Sharp K, Brindle PM, Brown MW, Turner GM. Memory loss during pregnancy. International J Obstet Gynaecol. 2009;100(3):209-15.

Cite this article as: Srinivasan V, Meerasa SS. Analysis of relationship between memory functions and blood indices across parturition in primigravidae. Int J Reprod Contracept Obstet Gynecol 2017;6:1455-60. 